\title{
Naves et communes limitrophes
}

Fabien Loubignac

URL : http://journals.openedition.org/adlfi/7288

ISSN : 2114-0502

Éditeur

Ministère de la culture

Référence électronique

Fabien Loubignac, «Naves et communes limitrophes », ADLFI. Archéologie de la France - Informations [En ligne], Limousin, mis en ligne le 01 mars 2007, consulté le 26 avril 2019. URL : http:// journals.openedition.org/adlfi/7288

Ce document a été généré automatiquement le 26 avril 2019

(c) Ministère de la Culture et de la Communication, CNRS 


\title{
Naves et communes limitrophes
}

\author{
Fabien Loubignac
}

\author{
Identifiant de l'opération archéologique : 2742 \\ Date de l'opération : 2006 - 2008 (PR) \\ Inventeur(s) : Loubignac Fabien (BEN)
}

1 Comme la première année de prospection (2006-2007) et cette deuxième année (2007-2008), ces recherches de terrain entrent dans le cadre d'un master II d'archéologie ayant pour sujet «L'Occupation du sol autour du sanctuaire de Tintignac de la fin de la Protohistoire à la fin de l'Antiquité ». Nous avions déjà montré que l'agglomération secondaire gallo-romaine de Tintignac s'étendait sous forme d'habitats dispersés sur une superficie de 70 à 90 ha environ. D'autres concentrations importantes avaient été remarquées sur d'autres secteurs de la commune (Cézarin, Moulin du Bos, La Borie). Les vestiges gallo-romains étant davantage détectables en prospection que ceux appartenant à la fin de la Protohistoire, nous n'avions pas pu trouver d'indices de sites suffisamment parlants pour donner une quelconque zone d'occupation (habitats) contemporaine du sanctuaire gaulois de Tintignac. À défaut, nous avions mentionné hypothétiquement la possibilité de la présence d'un site de hauteur qui aurait pu être fortifié au second âge du Fer. Seuls des sondages nous permettraient d'affirmer ou d'infirmer cette hypothèse. Cependant, un site laténien avait été mis en évidence par des découvertes anciennes et par la fouille de silos (voir supra) sur le secteur de Cézarin. D’autres découvertes récentes situeraient peut-être une agglomération ouverte laténienne sous le bourg de Naves.

2 D'importants sites ont été découverts sur la commune de Saint-Jal où tout un ensemble (minières, nécropole, fanum ?, habitats, etc.) daté du II ${ }^{\mathrm{e}}$ et III ${ }^{\mathrm{e}}$ siècle de notre ère pourrait appartenir à une grande villa voire à une agglomération secondaire. De nombreux exemples comme celui-ci nous montrent qu'une constellation d'habitats dispersés ou de petites agglomérations gravitent autour de Tintignac à la période gallo-romaine.

LOUBIGNAC Fabien 
INDEX

Index chronologique : Empire romain, La Tène, Protohistoire Index géographique : Limousin, Corrèze (19), Naves operation Prospection (PR)

\section{AUTEURS}

\section{FABIEN LOUBIGNAC}

BEN 